The final publication is available at link.springer.com

\title{
Surface Characterization of Die Inserts used for LED Lamp Plastic Lenses
}

\author{
Ali Aidibe ${ }^{\mathrm{a}, *}$, Mojtaba Kamali Nejad ${ }^{\mathrm{a}}$, Antoine Tahan ${ }^{\mathrm{a}}$, Mohammad Jahazi $^{\mathrm{a}}$, Sylvain G. Cloutier ${ }^{\mathrm{b}}$ \\ ${ }^{a}$ Department of Mechanical Engineering, Ecole de Technologie Superieure (ETS), 1100 Notre-Dame West, Montreal H3C 1K3, Quebec, Canada \\ ${ }^{\mathrm{b}}$ Department of Electrical Engineering, ETS \\ * Corresponding author: Ali Aidibe, Ph.D. E-mail: ali.aidibe.1@etsmtl.net
}

\begin{abstract}
The main objective of this paper is to investigate the effect of material characteristics and manufacturing processes on the surface textures of diamond cut inserts used for injected plastic optics in lighting applications. An overview of surface texture measurement is presented followed by an experimental procedure developed on 18 different die insert samples. A list of profile (2D) and areal (3D) surface texture measurement parameters characterizing the surface of the different samples is presented. The results of the analysis show that the average absolute roughness $R_{a}$, which is commonly used in industry, is not the only parameter representing the surface texture and is not a reliable discriminator for different types of surface textures. By using a principal component analysis technique, a list of significant parameters is proposed for a more accurate characterization of the surfaces resulting from different high precision diamond cutting processes. It is shown that the proposed parameters can be considered as optimum descriptors of the condition of the surface in diamond cutting and are those that show the greatest sensitivity to process variables.
\end{abstract}

Keywords: Plastic lenses; Injection molding; Roughness; Surface texture; Surface topography; LED

\section{Introduction}

Light Emitting Diodes (LEDs) are being used with increasing frequency in automotive lamps as they offer very long service life and extreme vibration resistance, and can permit considerably shallower packaging compared to most bulb-type assemblies [1]. In LED units, lenses collect, concentrate, and ultimately diffuse the light beams in the desired directions [2]. Plastic lenses are preferred to glass ones as they offer higher styling freedom, lower weight, and easier integration opportunities in addition to their low cost [3]. The optical performance of a lens is the ultimate quality differentiator in a LED lighting system and as such intensive research is underway to produce a new generation of LED lamps with higher optical performance lenses [4].

The surface quality of the plastic lens is considered to be one of the most important, if not, the most important parameters defining its performance (quality). The manufacturing process of optical lenses is injection molding, which is the most common method of producing parts made of plastic material. The process involves injecting molten plastic at high pressure into the metallic mold shaped in the form of the pot. When the plastic cools and solidifies, the mold opens and the part is ejected. Parts with holes, springs, threads and undercuts can be produced with an injection molding process on a single operation. It is important to note that the metallic die material (alloy composition, grain size, etc.), die surface (roughness, 3D topography, waviness, etc.), and subsurface quality (white zone, damage to the subsurface layer, etc.) significantly influence the final surface quality of the die material, i.e., the interface with the plastic lens, and hence its optical properties [2]. At present, trial and error practices are used by industry to obtain optimum surface conditions. For example, milling and additional polishing are used for spherical die cavities and some non-spherical ones, but this method is not efficient for freeform surfaces. For high-precision surfaces, a stainless steel die is first prepared by milling followed by nickel coating and finally ultra-precision diamond cutting of the coated surface. However, very little information is available on the influence of processing conditions on the surface quality of die inserts used for production of LED optical lenses. This paper has the view to develop a better understanding of the above interactions. Its principal objective is to investigate the effect of material characteristics and manufacturing processes on the surface of die inserts. The generated data will allow to choose the optimal material and cutting process in order to obtain the desired surface quality of the die and hence the optical performance of the plastic lens. 
The remainder of this paper is organized as follows: an overview of the surface texture measurement is presented in Section 2. Section 3 describes an experimental surface analysis carried out on eighteen different manufactured inserts. In this regard, a list of profile (2D) and areal (3D) surface texture measurement parameters of the surface are extracted and presented in Section 4. The principal component analysis technique is then performed, followed by a discussion of the results. Finally, a summary is provided in Section 5.

\section{Surface topography}

Surfaces are not perfectly smooth and they always have some irregularities. An overview of different topics related to surface topography (also known as surface finish or surface texture) is presented in this section. Surface texture is conventionally defined as comprising roughness and waviness only, while surface topography is defined as including the error of form and flaws as well as the surface texture. Often the terms topography, roughness, and texture are used inter-changeably [5]. In the rest of this paper, the term "surface texture" will be employed. When measuring a surface, one must distinguish between form, waviness, and roughness. The form represents the shape of the surface (long wavelength) while the roughness represents small irregularities on top of that shape (small wavelength; micrometer scale). There is no clear limit where the form starts and where the roughness begins. This depends on the measurement's sampling length and the filtering techniques. The reader is referred to existing ISO 16610 and ASME B46.1 standards [6,7] for extensive details about filtering techniques.

\subsection{Why measure roughness?}

From a tribological point of view, there is normally an optimum roughness to ensure the best application of the principles of friction, lubrication, and wear between interacting surfaces in relative motion. For example, the interaction between a harder surface (which is too rough) and a softer one will lead to abrasive wear and high friction because the harder surface will penetrate the softer one. On the other hand, if both surfaces are smooth, a very large wear area of contact occurs and when these surfaces are sliding, high temperature may occur, causing high friction. The roughness controls how much the asperities penetrate into the other surface. It also influences the surface stress conditions, the lubrication regime, the friction, and the wear. There are also other reasons to measure surface roughness, for example in surface finishing, it is important to define the appearance of a surface, how smooth it is and how smooth it needs to be in order to communicate that in different engineering application levels in a company. Another area where surface roughness plays a role is electric conductivity, heat conduction and lighting applications. The surface textures of die inserts significantly influence the optical properties of injected plastic optics of this last [2]. Many factors influence the surface irregularities: e.g., the production/finish process, the material structure, and the use of the surface. The production process (like turning, milling, grinding, etc.) or the surface finishing process (like polishing, coatings) will create different appearance of the surface. Another factor that plays a significant role is the material structure. A very brittle material will create more sharp corner asperities while a more ductile material will probably result in a smoother pattern. The use of the surface will also influence how the surface roughness looks; for example, wearing it, running-in, and the presence of chemical action on the material (like corrosion) will also change the surface texture.

\subsection{Existing measurement methods for surface texture}

The most classical and still very often in use is the stylus profilometer instrument. One of the major problems when using the profilometer is that the tip radius (from 2 to $5 \mu \mathrm{m}$ ) is large to resolve very fine irregularities. Another problem is the possibility of damaging the surface (scratch) because of the applied force by the stylus tip. There is another type of stylus instruments, called, Scanning Probe Microscopy (SPM), which works with the same principles as a profilometer but at a much smaller scale; examples are Scanning Tunneling Microscopy (STM) and Atomic Force Microscopy (AFM). These instruments provide very fine and accurate details on small measuring areas. On the other hand, SPM can be a more expensive and sensitive equipment. An expert operator is required to use the equipment. Also, measurements on very small areas might lead to misinterpretations. In recent years, optical methods are increasingly used to obtain 3D direct measurements of surface roughness (e.g., the interferometry instrument). The main advantage of optical methods over the stylus is the no direct contact of the measuring device with the surface. However, in addition to their higher cost, optical measurements may be disturbed in presence of thin transparent films on the surface. It should be mentioned that surface texture measurements are never precise. All different techniques provide different answers. For considerable detail regarding methods for measuring surface texture, we refer the reader to the work done by the National Institute of Standards and Technology [5,8] as well as to the ISO 25178-6:2010 [9] standard. In this project, a laser confocal microscope has been selected to measure the surface texture of the eighteen inserts as described in Section 3 of this paper.

\subsection{Surface texture characterization}

The surface can be considered as a two-dimensional function $Z(x, y)$ defined on the entire $\mathbb{R} \times \mathbb{R}$ domain. 
There are different types of parameters for surface texture characterization. Originally, scientists took measurements on linear profiles - called a profile 2D characterization by metrologists - by looking at the height $z$ which is a function of $x$. Available profile 2D surface texture standards are presented in [7, 10-20]. If the intention is to measure a surface (that is supposed to measure a profile), then areal measurements (3D characterization) are made, and in this case, $z$ is a function of $x$ and $y$. Areal 3D surface texture standard is presented in [21].

The most common surface texture characterization parameters could be divided into five main types:

- Amplitude (height) parameters; that only depend on the vertical position $z$ (Table $1-\mathrm{a} 1, \mathrm{a} 2)$.

- Spatial parameters; that depends on the horizontal position of the feature in $x$ and $y$ (Table $1-\mathrm{b}$ ).

- Hybrid parameters (Table $1-\mathrm{c}$ ).

- Motif parameters (Table 1 - d).

- Lubrication performance evaluation parameters (Table $1-\mathrm{e} 1, \mathrm{e} 2)$

Table 1 2D and 3D Surface texture characterization parameters summary list

\begin{tabular}{|c|ll|}
\hline \multicolumn{3}{|c|}{ Profile (2D) parameters [7, 10-20] } \\
\hline a1 & $R_{p}$ & Maximum profile peak height of the roughness profile \\
& $R_{v}$ & Maximum profile valley depth of the roughness profile \\
& $R_{z}$ & Maximum height of the roughness profile \\
& $R_{c}$ & Mean height of the roughness profile elements \\
& $R_{t}$ & Total height of the roughness profile \\
& $R_{a}$ & Arithmetical mean deviation of the roughness profile \\
& $R_{q}$ & Root mean square deviation of the roughness profile \\
& $R_{s k}$ & Skewness of the roughness profile \\
b & $R_{k u}$ & Kurtosis of the roughness profile \\
c & $R_{s m}$ & Mean width of the roughness profile elements \\
d & $R_{\Delta q}$ & Root mean square slope of the roughness profile \\
e1 & $R_{\delta c}$ & Profile section height difference of the roughness profile \\
& $R_{k}$ & Vertical difference in the core section \\
& $R_{p k}$ & Height of protruding peak \\
& $R_{v k}$ & Height of protruding valley \\
\hline \multicolumn{3}{|c|}{ Areal (3D) parameters conforming to ISO 25178 [22] } \\
\hline a2 & $S_{q}$ & Root mean squared height \\
& $S_{s k}$ & Skewness \\
& $S_{k u}$ & Kurtosis \\
& $S_{p}$ & Maximum peak height \\
& $S_{v}$ & Maximum valley depth \\
& $S_{z}$ & Maximum height \\
& $S_{a}$ & Arithmetic mean height \\
& $S_{k}$ & Core roughness depth \\
& $S_{p k}$ & Reduced peak height \\
& $S_{v k}$ & Reduced valley depth \\
\end{tabular}

Despite the breadth of available 2D and 3D surface texture measurement parameters, professionals continue to evaluate and characterize surface finish solely on the value of the arithmetical mean deviation of the roughness profile $\left(R_{a}\right)$. One of the major problems with this approach is that different profiles can still have very close $R_{a}$ values [22]. Specifically, a surface with sharp spikes, deep pits, or general isotropy may all yield the same $R_{a}$. The problem becomes even crucial when high precision components need to be machined for high-tech applications (e.g., optical lens injection). These surfaces do not have the same texture, and as a result, their optical characteristics will be different. Therefore, there is a clear need for a list of significant parameters to distinguish the surface texture characteristics created by every individual machining process which also considers the workpiece's material. In 2010, Petropoulos et al. [23] provided an overview of the current knowledge on the association of surface texture with machining, along with recent advances in surface characterization and evaluation. In their study, various texture parameters, adopted, or not, by ISO standards and their distinctive impacts were considered. In 2013, Deltombe et al. [24] proposed a multiscale surface topography decomposition method as a new methodology to select, without preconceived opinions, the $3 \mathrm{D}$ roughness parameters relevant for discriminating different topographies. The material used in the above study was rolled stainless steel and was machined using an electrical discharge tool. In 2015, a study of the variations of areal parameters on machined surfaces was reported by Pawlus et al. [25]. They studied parameter variations tendencies for various types of measured surfaces and selected 3D parameters that were stable for surfaces, but sensitive to surface irregularities. Section 3 presents the proposed experimental procedure for surface texture characteristics investigation of die inserts used for injected plastic optics in lighting applications.

\section{Experimental procedure}

The aim of the experimental procedure is to measure, compare, and examine the surface texture of the most common die inserts used for high precision injected optic lenses. To this aim, a total of eighteen different die inserts were manufactured for examination. This experimental design intends to cover the most common materials and diamond cutting techniques.

\subsection{Sample descriptions}

The samples represent a combination of three different materials with four different manufacturing processes. Table 2 summarizes the samples and their overall dimensions. The materials used in these experiments are as follows: Toughmet, Nickel-Phosphor and Acrylic (PMMA). The first two materials are used commonly for diamond cut die inserts, and the last one is for direct machined lenses. The different machining processes are as follows: turning, fly-cutting, ruling, and milling by a diamond cutter. Extensive details about these processes could be found in [26]. The manufacturing process has been adapted in terms of feed rate, cuter diameter, and cutting speed, in order to ensure a theoretical roughness value $R_{a}$ equal to $20 \mathrm{~nm}$. The samples have been stored in a personalized vacuum chamber to avoid the possible oxidation in the air. 
Table 2 Experimental matrix

\begin{tabular}{|c|c|c|c|c|c|c|c|}
\hline \multirow{3}{*}{$\begin{array}{c}\begin{array}{c}\text { Experimental } \\
\text { design }\end{array} \\
\text { Tool radius }(\mu m) \\
\end{array}$} & \multicolumn{7}{|c|}{ Machining Process } \\
\hline & \multicolumn{2}{|c|}{ Turning } & \multirow{2}{*}{$\begin{array}{c}\begin{array}{c}\text { Fly- } \\
\text { cutting }\end{array} \\
100 \\
\end{array}$} & \multicolumn{2}{|c|}{ Ruling } & \multicolumn{2}{|c|}{ Milling } \\
\hline & 40 & 150 & & 40 & 150 & 150 & 500 \\
\hline $\begin{array}{l}\text { Maximum cutting } \\
\text { speed }(\boldsymbol{m} / \mathrm{min})\end{array}$ & 142 & 145 & 375 & 1.8 & 1.8 & 30 & 137 \\
\hline Pitch $(\mu m)$ & 4.2 & 8.3 & 6.8 & 4.2 & 8.3 & 8.4 & 15 \\
\hline $\begin{array}{l}\text { Feed per tooth } \\
(\mu \mathrm{m})\end{array}$ & - & - & 236 & - & - & 8.4 & 15 \\
\hline $\begin{array}{l}\text { Toughmet } \\
(3 \mathrm{AT} 110)\end{array}$ & T1 & $\mathbf{T} 2$ & T3 & T4 & T5 & T6 & T7 \\
\hline $\begin{array}{ll}\text { Nickel } \\
\text { Phosphor }\end{array}$ & N1 & $\mathbf{N} 2$ & N3 & N4 & N5 & N6 & N7 \\
\hline $\begin{array}{l}\text { Acrylic } \\
\text { (PMMA) }\end{array}$ & A1 & A2 & & A3 & A4 & & \\
\hline & \multicolumn{3}{|c|}{$\begin{array}{l}\text { Example of insert } \\
(\emptyset 10 \mathrm{~mm}, \\
\text { height }=16 \mathrm{~mm})\end{array}$} & & & & \\
\hline
\end{tabular}

\subsection{Measurement protocol and repeatability test}

The surface roughness measurements were carried out using a Confocal Digital Microscope Olympus LEXT OLS4100 unit provided at the École de Technologie Superieure's Products, Processes, and Systems Engineering Laboratory (ÉTS-P2SEL) in Montréal (QC), Canada. The unit is a laser scanning microscope that performs non-contact 3D observations and measurements of surface features. Its specifications could be found in [27]. The LEXT OLS4100 microscope has been checked for repeatability using the KNT 4070/03 ultrafine roughness reference part. It was provided by HALLE Präzisions-Kalibriernormale $\mathrm{GmbH}$ Inc. for calibration and for the verification of roughness measurement instruments [28]. This reference part is measured and calibrated (tracableto PhysikalischTechnische Bundesanstalt (PTB) standards). The body of the reference part consists of hardened stainless steel, $40 \mathrm{~mm} \times 20 \mathrm{~mm} \times 11.3 \mathrm{~mm}$. A rectangular measuring surface, $5 \mathrm{~mm} \times 9 \mathrm{~mm}$, made of hardened nickel is diamond turned in the middle of the body. In order to perform the repeatability test of the microscope, 25 measures were made on the reference part. The results presented in Table $3 \mathrm{a}$ show that the average roughness $\left(R_{a}\right)$ and the mean roughness depth $\left(R_{z}\right)$ values are close to the ones provided by the KNT 4070/03 reference part.

Surface (3D images) can be described as a function $Z(x, y)$ defined on the entire $\mathbb{R} \times \mathbb{R}$ domain. Measurements taken by the confocal microscope sampled this function, at discrete points in a finite area. 3D images of $400 \mu \mathrm{m} \times 400 \mu \mathrm{m}$ were captured using an objective lens wit $\times 50$ magnification. These dimensions are selected based on the recommendation for the evaluation length provided in [6]. The Olympus microscope software uses a Gaussian probability function in order to separate the waviness from the roughness (filtering). This was done using a cut-off value $\lambda_{c}$ of $0.08 \mathrm{~mm}$ as recommended by the standards [6,7]. For each insert, a total of five different positions were $3 \mathrm{D}$ imaged. One areal and five profile surface texture measurements were extracted per image (5 areal and 25 profile surface texture measurements per insert). Table $3 \mathrm{~b}$ presents the repeatability study results of the 25 profile measures taken on T1 sample. This was done in order to verify the repeatability of the process on the entire insert surface and the quality of the deposited material on each insert. The results of the characterization are provided in the next section.

Table 3 Repeatability results

\begin{tabular}{|c|c|c|c|c|}
\hline \multicolumn{5}{|c|}{ (a) Repeatability of the measurement system ( 25 measures) } \\
\hline & \multicolumn{2}{|c|}{ KNT 4070/03 } & \multicolumn{2}{|c|}{ Measured (LEXT) } \\
\hline & $R_{a}[\mathrm{~nm}]$ & $R_{z}[\mathrm{~nm}]$ & $R_{a}[\mathrm{~nm}]$ & $R_{z}[\mathrm{~nm}]$ \\
\hline Max. & 29.2 & 164.0 & 31.0 & 165.0 \\
\hline Mean & 26.5 & 146.4 & 26.8 & 141.0 \\
\hline Min. & 23.9 & 128.8 & 25.0 & 125.0 \\
\hline \multicolumn{5}{|c|}{ (b) Repeatability of the measures taken on $\mathrm{T} 1$ sample ( 25 measures) } \\
\hline & $R_{a}[\mathrm{~nm}]$ & $R_{q}[\mathrm{~nm}]$ & & \\
\hline Mean & 16.0 & 20.0 & & \\
\hline Standard deviation & 1.7 & 2.2 & & \\
\hline
\end{tabular}

\section{Results and discussion}

$3 \mathrm{D}$ views of the surface texture of certain samples are presented in Figure 1 and Figure 2. The profile and areal surface texture measurement parameters presented in Table 1 were extracted from the surface of each die insert as described in the measurement protocol. Table 4 and Table 5 present their median values in the order of a same machining process.

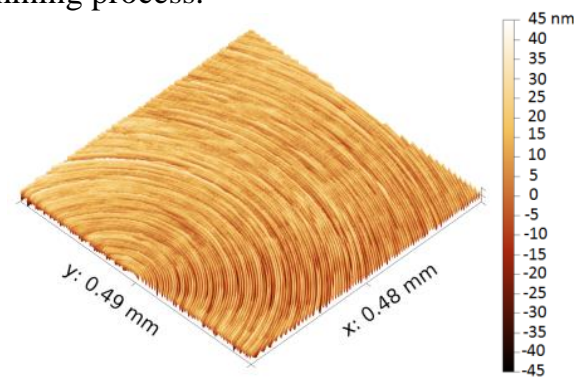

(a)

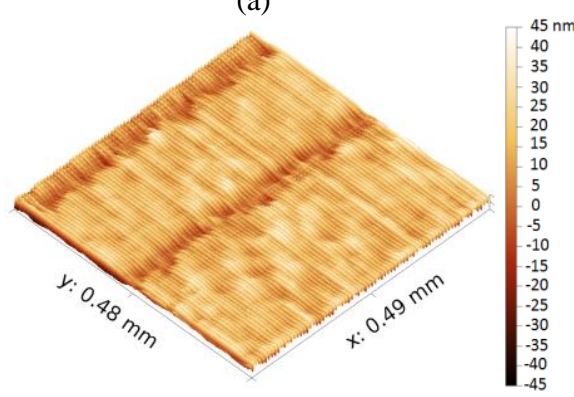

(b)

Figure 1 3D views of the surface texture for some inserts: (a) Turning A1 (b) Fly-cutting N3 


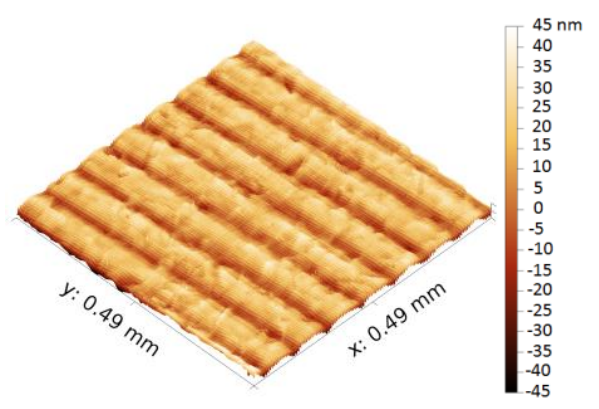

(a)

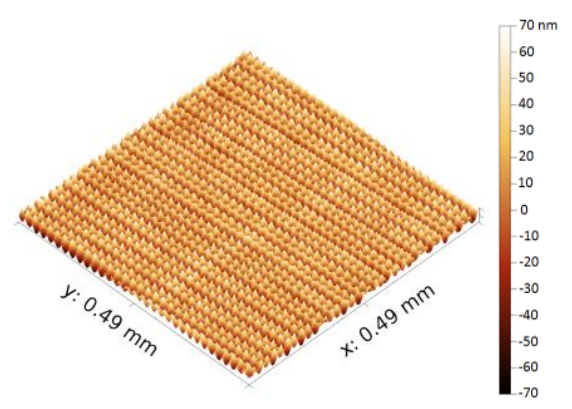

(b)

Figure 2 3D views of the surface texture for some inserts: (a) Ruling T4 (b) Milling N7

Table 4 Profile 2D surface texture parameter results

\begin{tabular}{|c|c|c|c|c|c|c|c|c|c|c|c|c|c|c|c|c|}
\hline \multirow{2}{*}{\multicolumn{2}{|c|}{ Samples }} & \multicolumn{15}{|c|}{ 2D Parameters - Median value $(\boldsymbol{\mu m})$} \\
\hline & & $R_{p}$ & $R_{v}$ & $R_{z}$ & $R_{c}$ & $R_{t}$ & $R_{a}$ & $R_{q}$ & $R_{s k}$ & $R_{k u}$ & $R_{s m}$ & $R_{\Delta q}$ & $R_{\delta c}$ & $R_{k}$ & $R_{p k}$ & $R_{v k}$ \\
\hline \multirow{6}{*}{ 番 } & T1 & 0.051 & 0.038 & 0.090 & 0.061 & 0.126 & 0.016 & 0.019 & 0.539 & 2.547 & 4.369 & 2.23 & 0.036 & 0.045 & 0.025 & 0.011 \\
\hline & N1 & 0.051 & 0.030 & 0.079 & 0.062 & 0.102 & 0.016 & 0.019 & 0.760 & 2.620 & 4.179 & 2.22 & 0.035 & 0.039 & 0.029 & 0.003 \\
\hline & A1 & 0.048 & 0.030 & 0.080 & 0.057 & 0.103 & 0.015 & 0.018 & 0.712 & 2.628 & 4.265 & 2.03 & 0.0325 & 0.039 & 0.025 & 0.007 \\
\hline & $\mathrm{T} 2$ & 0.045 & 0.039 & 0.080 & 0.057 & 0.118 & 0.013 & 0.016 & 0.687 & 3.03 & 8.302 & 1.28 & 0.028 & 0.033 & 0.028 & 0.012 \\
\hline & N2 & 0.048 & 0.030 & 0.078 & 0.059 & 0.109 & 0.013 & 0.016 & 0.791 & 3.075 & 8.307 & 1.272 & 0.028 & 0.028 & 0.027 & 0.007 \\
\hline & A2 & 0.049 & 0.028 & 0.079 & 0.056 & 0.092 & 0.014 & 0.017 & 0.664 & 2.648 & 8.480 & 1.07 & 0.031 & 0.036 & 0.027 & 0.007 \\
\hline \multirow{5}{*}{ 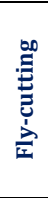 } & T3 & 0.048 & 0.036 & 0.083 & 0.061 & 0.105 & 0.016 & 0.018 & 0.598 & 2.494 & 6.613 & 1.56 & 0.034 & 0.037 & 0.027 & 0.008 \\
\hline & N3 & 0.050 & 0.030 & 0.081 & 0.059 & 0.090 & 0.016 & 0.019 & 0.617 & 2.481 & 6.616 & 1.42 & 0.034 & 0.039 & 0.027 & 0.007 \\
\hline & T4 & 0.062 & 0.050 & 0.114 & 0.060 & 0.134 & 0.019 & 0.023 & 0.191 & 2.651 & 6.098 & 2.09 & 0.040 & 0.060 & 0.025 & 0.019 \\
\hline & N4 & 0.054 & 0.031 & 0.085 & 0.064 & 0.107 & 0.016 & 0.020 & 0.705 & 2.591 & 4.177 & 2.34 & 0.036 & 0.045 & 0.028 & 0.007 \\
\hline & A3 & 0.052 & 0.041 & 0.092 & 0.058 & 0.110 & 0.017 & 0.020 & 0.232 & 2.337 & 5.307 & 2.08 & 0.038 & 0.055 & 0.017 & 0.009 \\
\hline \multirow{3}{*}{$\stackrel{\infty 00}{\Xi}$} & T5 & 0.047 & 0.031 & 0.079 & 0.054 & 0.097 & 0.014 & 0.017 & 0.553 & 2.710 & 8.583 & 1.10 & 0.030 & 0.046 & 0.022 & 0.013 \\
\hline & N5 & 0.045 & 0.027 & 0.073 & 0.052 & 0.087 & 0.014 & 0.017 & 0.625 & 2.658 & 8.519 & 1.00 & 0.029 & 0.043 & 0.022 & 0.010 \\
\hline & A4 & 0.051 & 0.047 & 0.099 & 0.059 & 0.125 & 0.017 & 0.021 & 0.09 & 2.758 & 10.053 & 1.15 & 0.035 & 0.054 & 0.020 & 0.023 \\
\hline \multirow{4}{*}{$\stackrel{\infty 0}{.}$} & T6 & 0.066 & 0.066 & 0.132 & 0.085 & 0.181 & 0.023 & 0.027 & -0.118 & 2.358 & 8.124 & 3.94 & 0.050 & 0.084 & 0.019 & 0.021 \\
\hline & N6 & 0.063 & 0.059 & 0.123 & 0.085 & 0.145 & 0.020 & 0.029 & 0.010 & 2.077 & 8.469 & 2.04 & 0.055 & 0.090 & 0.010 & 0.010 \\
\hline & T7 & 0.055 & 0.048 & 0.104 & 0.077 & 0.128 & 0.020 & 0.024 & 0.302 & 2.274 & 16.180 & 1.13 & 0.044 & 0.050 & 0.020 & 0.010 \\
\hline & N7 & 0.053 & 0.041 & 0.094 & 0.070 & 0.112 & 0.020 & 0.023 & 0.235 & 2.141 & 16.620 & 0.97 & 0.045 & 0.060 & 0.010 & 0.010 \\
\hline
\end{tabular}

Table 5 Areal 3D surface texture parameter results

\begin{tabular}{|c|c|c|c|c|c|c|c|c|c|c|c|}
\hline \multirow{2}{*}{\multicolumn{2}{|c|}{ Samples }} & \multicolumn{10}{|c|}{ 3D Parameters - Median value $(\mu m)$} \\
\hline & & \multirow{2}{*}{$\begin{array}{c}S_{q} \\
0.021\end{array}$} & \multirow{2}{*}{$\begin{array}{c}S_{S k} \\
0.662\end{array}$} & \multirow{2}{*}{$\begin{array}{c}S_{k u} \\
12.315\end{array}$} & \multirow{2}{*}{$\begin{array}{c}S_{p} \\
1.237\end{array}$} & \multirow{2}{*}{$\begin{array}{c}S_{v} \\
0.689\end{array}$} & \multirow{2}{*}{$\begin{array}{c}S_{z} \\
1.888\end{array}$} & \multirow{2}{*}{$\begin{array}{c}S_{a} \\
0.017\end{array}$} & \multirow{2}{*}{$\begin{array}{c}S_{k} \\
0.048\end{array}$} & \multirow{2}{*}{$\begin{array}{c}S_{p k} \\
0.025\end{array}$} & \multirow{2}{*}{$\begin{array}{c}S_{v k} \\
0.013\end{array}$} \\
\hline \multirow{6}{*}{ Turning } & T1 & & & & & & & & & & \\
\hline & N1 & 0.019 & 0.766 & 3.247 & 0.393 & 0.211 & 0.638 & 0.015 & 0.042 & 0.028 & 0.006 \\
\hline & A1 & 0.022 & 0.586 & 3.352 & 0.477 & 0.515 & 1.071 & 0.018 & 0.054 & 0.025 & 0.011 \\
\hline & T2 & 0.017 & 0.673 & 7.798 & 0.618 & 0.692 & 1.008 & 0.013 & 0.033 & 0.025 & 0.011 \\
\hline & N2 & 0.017 & 0.850 & 3.655 & 0.214 & 0.154 & 0.368 & 0.014 & 0.029 & 0.027 & 0.008 \\
\hline & A2 & 0.022 & 0.498 & 3.189 & 0.406 & 0.197 & 0.603 & 0.018 & 0.058 & 0.026 & 0.011 \\
\hline \multirow{5}{*}{ Fly-cutting } & T3 & 0.018 & 0.493 & 4.880 & 0.426 & 0.589 & 1.106 & 0.015 & 0.039 & 0.024 & 0.009 \\
\hline & N3 & 0.018 & 0.530 & 2.897 & 0.404 & 0.360 & 0.715 & 0.015 & 0.043 & 0.022 & 0.008 \\
\hline & $\mathrm{T} 4$ & 0.024 & 0.489 & 4.191 & 1.510 & 0.638 & 2.149 & & 0.060 & 0.024 & 0.018 \\
\hline & N4 & 0.020 & 0.727 & 3.132 & 0.443 & 0.328 & 0.791 & 0.016 & 0.044 & 0.029 & 0.007 \\
\hline & A3 & 0.021 & 0.313 & 4.280 & 0.520 & 0.472 & 1.077 & 0.017 & 0.055 & 0.017 & 0.010 \\
\hline \multirow{3}{*}{ Ruling } & T5 & 0.018 & 0.350 & 7.641 & 0.740 & 0.821 & 1.430 & 0.014 & 0.042 & 0.022 & 0.010 \\
\hline & N5 & 0.017 & 0.605 & 2.885 & 0.170 & 0.119 & 0.255 & 0.014 & 0.039 & 0.021 & 0.007 \\
\hline & A4 & 0.021 & -0.001 & 3.042 & 0.333 & 0.313 & 0.598 & 0.017 & 0.051 & 0.020 & 0.021 \\
\hline \multirow{4}{*}{ Milling } & T6 & 0.029 & -0.078 & 4.233 & 0.523 & 0.712 & 1.525 & 0.024 & 0.083 & 0.020 & 0.021 \\
\hline & N6 & 0.030 & 0.045 & 2.845 & 0.655 & 0.405 & 1.213 & 0.025 & 0.090 & 0.018 & 0.017 \\
\hline & T7 & 0.027 & 0.256 & 3.075 & 0.555 & 0.626 & 1.081 & 0.023 & 0.080 & 0.023 & 0.011 \\
\hline & N7 & 0.027 & 0.196 & 2.426 & 0.306 & 0.104 & 0.446 & 0.022 & 0.077 & 0.023 & 0.012 \\
\hline
\end{tabular}


The preliminary analysis of the surface characterization results shows that:

- The most common parameter in industry $R_{a}\left(S_{a}\right)$ is not very useful to describe the behavior of the surface from a tribological point of view. As shown in Figure 3, and Table 4 and Table 5, different machining processes fail into approximately the same $R_{a}\left(S_{a}\right)$ values. These common parameters could not be considered as a reliable discriminator of different surface texture types that leads to different optical performances.

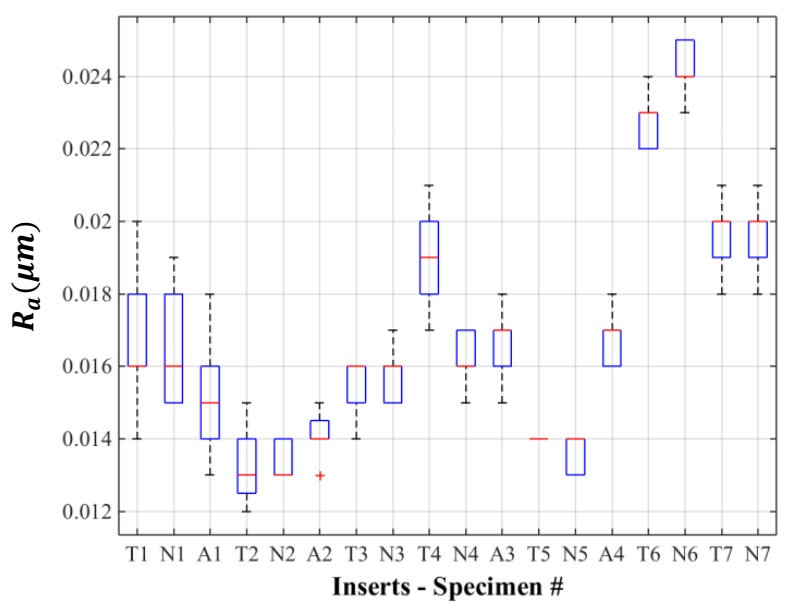

Figure 3 Box plot; $R_{a}$-Samples presented in the order of a same machining process

- As shown in Figure 4, the mean width of the roughness profile elements $R_{s m}$ could be among the best to describe the surface texture. Samples belonging to the same machining process are grouped together. Another way could be the bearing ratio curve (cumulative distribution) represented by the parameter $R_{k}\left(S_{k}\right), R_{p k}$ and $R_{v k}$.

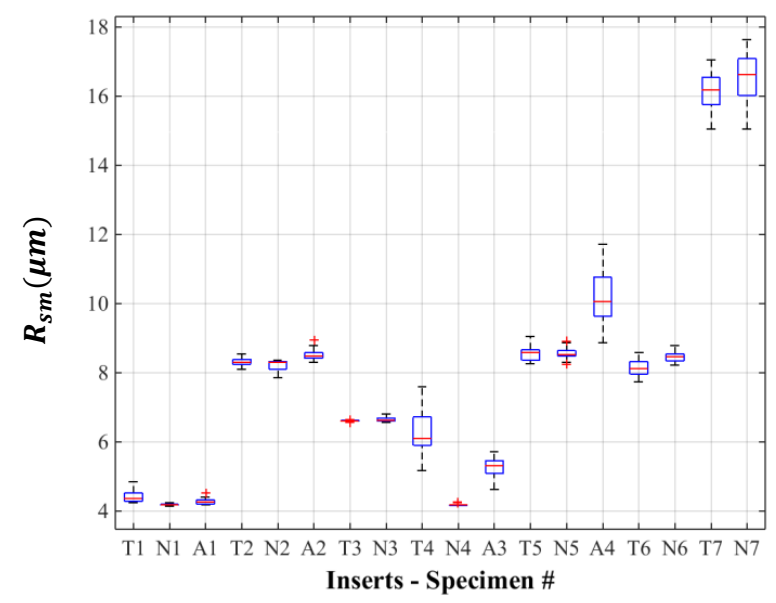

Figure 4 Box plot; $\boldsymbol{R}_{s m}$ - Samples presented in the order of a same machining process
- From a functional point of view, concerning the patterned textures, the slope is actually more important than the height. It shows how sharp asperities are. The slope has a closer correlation to tribological phenomenon like friction and wear. Therefore, slope $R_{\Delta q}$ (Figure 5) can describe in a better way the different surface textures rather than height $R_{a}$.

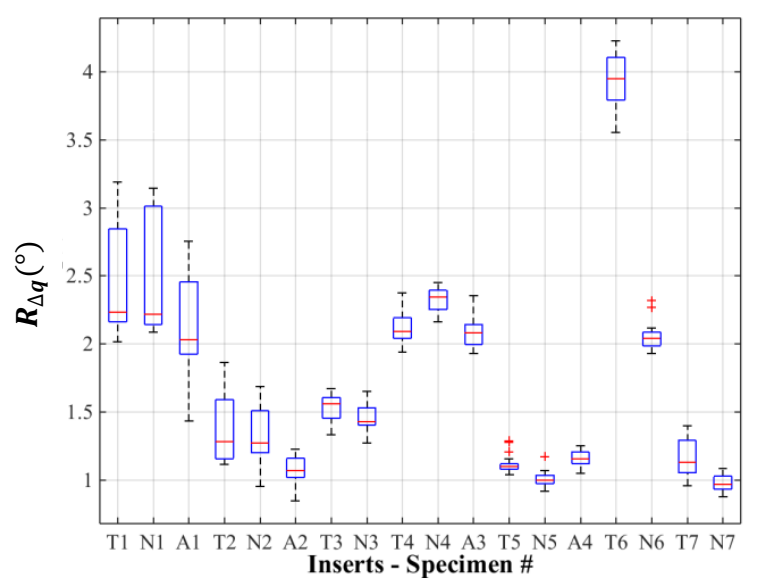

Figure 5 Box plot; $R_{\Delta q}$-Samples presented in the order of a same machining process

As stated in the introduction, distinguishing different surface textures obtained by ultra-precision manufacturing processes using diamond cutting tools for optical applications is crucial because it leads to different optical performances. For that matter, a Principal Component Analysis (PCA) is used in the next section to better highlight the similarities and differences between the various surface texture measurement parameters and to identify possible patterns among them

\subsection{The Principal Component Analysis}

The Principal Component Analysis (PCA) is the statistical, descriptive, or exploratory method invented by Pearson [29] and Hotelling [30] used to extract the main sources of variation in multi-variate datasets. PCA is a change of variable space that reduces the original dimensionality into a lower number of orthogonal non correlated synthesized variables.

In the current study, two PCAs (PCA-R, PCA-S) were conducted separately on the surface texture measurement parameters (2D and 3D). For both PCAs, the individuals are the eighteen different die inserts. The quantitative variables for PCA-R study are the profile surface texture parameters. The quantitative variables for PCA-S study are the areal surface texture measurement parameters.

The Scree Plot for PCA-R and PCA-S presented in Figure $6 \mathrm{a}$, Figure $6 \mathrm{~b}$, respectively, are related to the eigenvalues, which reflect the quality of the projection 
from the $N$-dimensional initial table ( $N=15$ for PCAR; $N=10$ for PCA-S) to a lower number of dimensions. The Scree Plot for PCA-R and PCA-S shows that three of those eigenvalues explain most of the variability, ensuring that the maps based on the first three factors are a good quality projection of the initial multi-dimensional table. The remaining factors explain a very small proportion of the variability and are likely unimportant. In Figure 6a, the first eigenvalue equals 10.7 and represents $70 \%$ of the total variability. This means that if the data is represented only on one axis, it will be still possible to see $70 \%$ of the total variability of the data. In the case of Scree Plot for 2D parameters (Figure 6a), the three components with eigenvalues greater than or equal to 1,0 were extracted. Together, they account for $92 \%$ of the variability in the original data. Similarly, as shown in Figure $6 b$, the three components with eigenvalues greater than or equal to 1.0 account for $89 \%$ of the variability in the original data.

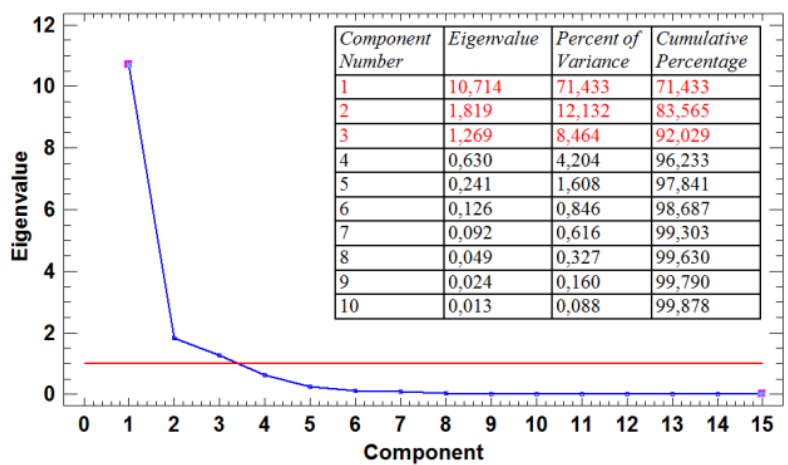

(a)

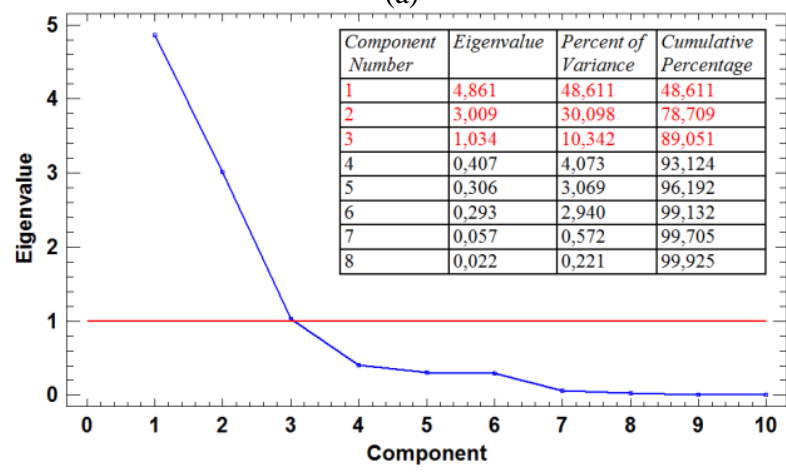

(b)

Figure 6 PCA results; Scree Plot: (a) for 2D parameters (b) for 3D parameters

Figure 7a is a Loading Plot from the PCA-R. Variables that are closely correlated from a statistical point of view have been grouped together. The first component (PCA1-R) in the horizontal direction, which is the most important one, is positively correlated with the amplitude parameters (Table 1a) and negatively correlated with the skewness parameter $\left(R_{s k}\right)$ while the second component (PCA2-R) is significantly positively correlated with the spatial parameters $\left(R_{s m}\right)$ and significantly negatively correlated with the Slope $\left(R_{\Delta q}\right)$. On the other side, Loading Plot from the PCA-S is presented in Figure 7b. PCA1-S in the horizontal direction is negatively correlated with Skewness parameter $\left(S_{s k}\right)$. The second component (PCA2-S) in the vertical direction is positively correlated with Kurtosis $\left(S_{k u}\right)$.

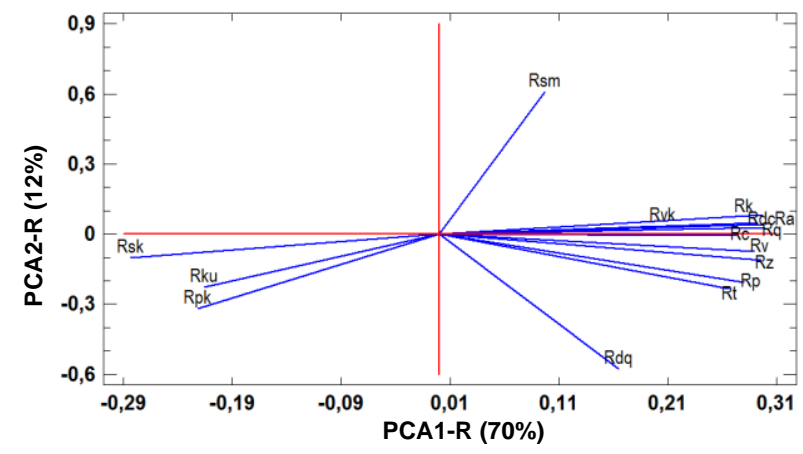

(a)

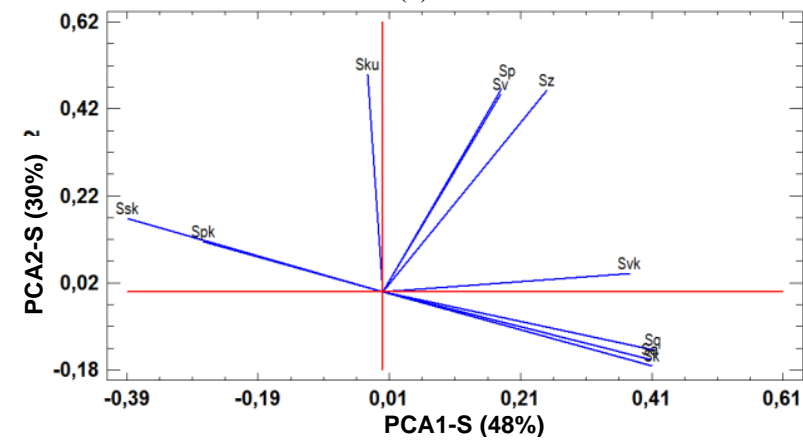

(b)

Figure 7 PCA results; Loading Plot: (a) for 2D parameters (b) for 3D parameters

Finally, in the Score Plot presented in Figure 8 the different machining processes studied in this paper are displayed according to the two main components. A clear trend is noticed in Figure 8a showing how a particular machining process is positioned when considering the main variables (PCA-R components).

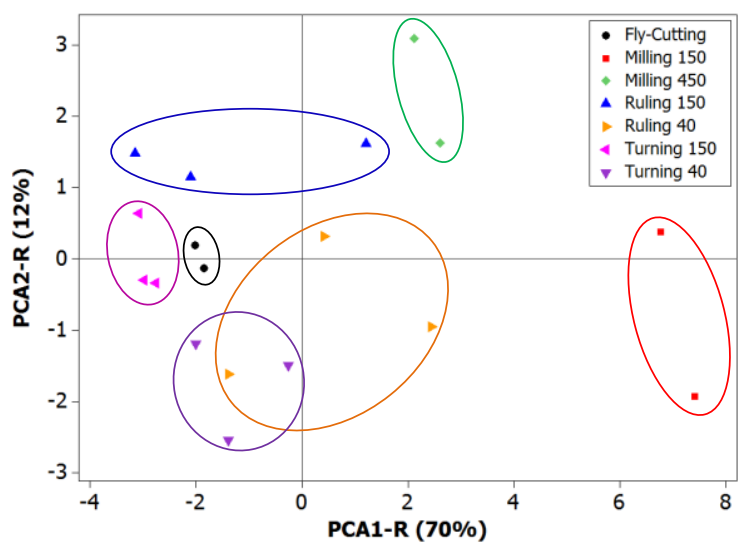

Figure 8 PCA results; Score plot for 2D parameters 


\section{Conclusion}

A combined experimental and analytical surface texture analysis study carried out on eighteen diamond cut die inserts used for injected plastic optics in lighting applications was presented in this paper. The aim was to investigate the effect of different diamond turning processes and materials and identify the critical parameters characterizing the surface quality of the diamond cut inserts.

The results confirm that $R_{a}\left(\operatorname{or} S_{a}\right)$ alone is not a reliable discriminator of surface texture generated by different machining processes.

Based on the principal component analysis, a group of surface texture parameters need to be taken into consideration for a better description of the surface texture. The first element of the proposed group is the amplitude parameters (e.g., height $R_{a}, R_{z}, .$. and skewness $R_{s k}$ ). The second element is the spatial parameter $R_{S m}$ and the third one is the root mean square slope $R_{\Delta q}$.

The proposed group will allow industries to better distinguish different surface textures obtained from the diamond cutting process. The proposed parameters are considered as optimum descriptors of the condition of the surface and are those that show the greatest sensitivity. This may result in cost saving while reducing the production time and therefore increasing the global competitiveness. The findings of the project will be also directly applicable to other industries that use diamond turning process such as aerospace and satellite manufacturing sectors. In the next phase of the project, the optical performance of the injected lens (diffractive surface, Total Internal Reflection TIR, scattering, etc.) will be modeled as a function of the proposed group.

\section{Acknowledgments}

The authors would like to thank the National Sciences and Engineering Research Council (NSERC) and the École de Technologie Supérieure (ÉTS, Québec, Canada) for their support and financial contribution.

\section{References}

[1] Flannagan, M. and Sivak, M. (1989). An improved braking indicator. SAE Technical Paper 890189.

[2] Bäumer, S. (2005). Handbook of plastic optics. Wiley$V G H$, Weinheim.

[3] Stauss, B. (2011). High precision plastic lenses-styling, optical design, manufacturing process. Proceedings of ISAL, Darmstadt, Germany.
[4] Automotive Learning Center. Plastics \& today's automobiles: Car lighting systems. American Chemistry Council.

[5] Vorburger, T.V. (1990). Methods for characterizing surface topography. National Institute of Standards and Technology. Gaithersburg, Maryland 20899.

[6] ISO 16610 series. Geometrical product specifications (GPS) - Filtration. International Organization for Standardization, Geneva.

[7] ASME B46.1 (2009). Surface texture (Surface roughness, waviness, and lay). The American Society of Mechanical Engineers, New York.

[8] Vorburger, T. V. (1990). Surface finish metrology tutorial. National Institute of Standards and Technology, Gaithersburg, Maryland 20899.

[9] ISO 25178-6:2010. Geometrical product specifications (GPS) -- Surface texture: Areal -- Part 6: Classification of methods for measuring surface texture. International Organization for Standardization, Geneva.

[10] ISO 1302:2002. GPS - Indication of surface texture in technical product documentation. International Organization for Standardization, Geneva.

[11] ISO 3274:1996. GPS - Surface texture: Profile method Nominal characteristics of contact (stylus) instruments. International Organization for Standardization, Geneva.

[12] ISO 4287:1997. GPS - Surface texture: Profile method Terms, definitions and surface texture parameters. International Organization for Standardization, Geneva.

[13] ISO 4288:1996. GPS - Surface texture: Profile method Rules and procedures for the assessment of surface texture. International Organization for Standardization, Geneva.

[14] ISO 5436-1:2000. GPS - Surface texture: Profile method Measurement standards - Part 1: Material measures. International Organization for Standardization, Geneva.

[15] ISO 5436-2:2012. GPS - Surface texture: Profile method Measurement standards - Part 2: Software measurement standard. International Organization for Standardization, Geneva.

[16] ISO 12085:1996. GPS - Surface texture: Profile method Motif parameters. International Organization for Standardization, Geneva.

[17] ISO 12179:2000. GPS - Surface texture: Profile method Calibration of contact (stylus) instruments. International Organization for Standardization, Geneva.

[18] ISO 13565-1:1996. GPS - Surface texture: Profile method - Surfaces having stratified functional properties - Part 1: Filtering and general measurement conditions. International Organization for Standardization, Geneva.

[19] ISO 13565-2:1996. GPS - Surface texture: Profile method - Surfaces having stratified functional properties - Part 2: Height characterization using the linear material ratio curve. International Organization for Standardization, Geneva. [20] ISO 13565-2:1998. GPS - Surface texture: Profile method - Surfaces having stratified functional properties - Part 3: Height characterization using the material probability curve. International Organization for Standardization, Geneva. 
[21] ISO 25178. GPS - Surface texture: Areal. International Organization for Standardization, Geneva.

[22] Bharat, B. (2000). Modern tribology handbook. CRC Press, vol. 1, p. 49-50.

[23] Petropoulos, G. (2010). Surface texture characterization and evaluation related to machining. Surface Integrity in Machining, Springer, p. 37-66.

[24] Deltombe R, Kubiak KJ and Bigerelle M. How to select the most relevant 3D roughness parameters of a surface. Scanning - Wiley; 2013 vol. 36, issue 1, p.150-160

[25] Pawlus P, Graboń W, Reizer R. and Górka S. A study of variations of areal parameters on machined surfaces. Surface Topography: Metrology and Properties; 2015 vol. 3.

[26] ASM Handbook vol. 16. Machining. The American Society for Metal (ASM) International; 1989.
[27] Industrial Microscopes OLS4100. Retreived January 2016, from:

http://www.olympus-

ims.com/en/metrology/ols4100/\#!cms[tab]=\%2Fmetrology\%2 Fols $4100 \% 2$ Fspecifications

[28] Calibration standards. (corresponding to PTBmeasurement standards). Retrieved Novembre 2015, from: http://www.halle-

normale.de/pdf/2013/englisch/HALLE_catalog_2013-2014.pdf [29] Pearson, K. (1901). On lines and planes of closest fit to systems of points in space. Philosophical Magazine, series 6, vol. 2, no. 11, p. 559-572.

[30] Hotelling, H. (1933). Analysis of a complex of statistical variables into principal components. Journal of Educational Psychology, vol. 24, p. 417-441 and 498-52. 